\title{
Bilateral Loss of Vision after Spinal Anaesthesia on a Dwarf Patient
}

\author{
Kassa $\mathrm{MW}^{1 *}$, Shifa $\mathrm{JZ}^{2}$, Bekele $\mathrm{NA}^{3}$,Opondo $\mathrm{PR}^{4}$ \\ ${ }^{1}$ Department of Anesthesia and Critical Care Medicine, University of Botswana, Botswan; ${ }^{2}$ Department of Surgery, University \\ of Botswana, Botswana; ${ }^{3}$ Bokamoso Private Hospital, Botswana; ${ }^{4}$ Department of Psychiatry, University of Botswana, Botswana
}

\begin{abstract}
Achondroplasia is the most common form of dwarfism. Achondroplasia poses multiple anaesthetic challenges ranging from securing intravenous line, monitoring and drug dose calculations and airway management among others. Spinal anaesthesia is a very common method of anaesthesia in Botswana. The only type of anaesthetic drug that is in use for spinal anaesthesia in Botswana is hyper baric bupivacaine $0.5 \%$. We report a case of a 33-year-old achondroplastic dwarf patient who developed bilateral visual loss for three days after he had received spinal anaesthesia for appendectomy. Postoperatively the patient was found to have increased intracranial pressure on magnetic resonance imaging scan. Subsequently decompressive ventriculo-peritoneal shunt operation was done and he gradually regained his vision. Meticulous and detailed pre anaesthetic assessment, well planned mode of anaesthesia and post-operative care of dwarf patients is essential to minimize complications and its severity. Postoperative signs and symptoms that may indicate any neurological effect of high intracranial pressure on dwarf patients have to be promptly identified and treated urgently to reduce further damage.
\end{abstract}

Keywords: Dwarf; Loss of vision; Spinal anaesthesia

\section{INTRODUCTION}

Achondroplastic dwarfism is the commonest form of skeletal dysplasia. It involves multiple organ system defects which can lead to anaesthetic challenge. It poses multiple anaesthetic challenges ranging from securing intravenous line, monitoring and drug dose calculations to airway, spine thoracic cage, cardiopulmonary and neurological symptoms.

Postoperative visual loss (POVL) is a rare complication of anaesthesia, with increased prevalence after cardiac, spine, head and neck, and some orthopaedic procedures. The most common causes of permanent POVL are central retinal artery occlusion, ischemic optic neuropathy, and cerebral vision loss [1]. In some situations of visual loss an organic cause of the problem might not be found. A diagnosis of non-organic visual loss requires both the absence of any physical findings on examination and proof of the integrity and functioning of the visual system [2]. Psychiatric evaluation may be helpful to help identify a conversion disorder. Various causes attributed to postoperative blindness include ischemic optic neuropathy, central or branch retinal artery occlusion, cortical blindness, and rarely external ocular injury.
Contributory factors described are micro vascular diseases and intraoperative hemodynamic compromise [3].

In total cortical blindness pupillary reflexes are preserved and most of the visual field is restored within days. Cortical blindness can result from global or focal ischemia, cardiac arrest, hypoxemia, vascular occlusion, thrombosis, intracranial haemorrhage, vasospasm, and emboli [3]. Two case reports of Urethral resection of 73 and 74 years old men under spinal anaesthesia have been reported for loss of vision where the cause was said to be secondary to the use of Glycine for urethral irrigation [4].

In 2015 there was a rare complication published of transient bilateral hearing loss of a patient for three days after spinal anaesthesia for which the cause was not clearly established [5].

Achondroplasia is the most common type of dwarfism. Recent studies have cited incidence rates of Achondroplasia to be 1:21,800 live births. Common features of Achondroplasia include decreased limb length (proximal segments shorter than the distal), a large head with prominent forehead, flattened midface with a depressed nasal bridge, a prominent mandible and abnormal shape of the head. Chest and spinal curvature brings possibility of difficulty of positioning, intubation and ventilation. Possibility of compression

Correspondence to: Kassa MW, Faculty of Medicine, Department of Anesthesia and Critical Care Medicine, University of Botswana, Botswana, Tel: +26775780409; E-mail: mwoldu@ymail.com

Received: June 01, 2021; Accepted: June 14, 2021; Published: June 21, 2021

Citation: Kassa MW, Shifa JZ, Bekele NA, Opondo PR (2021) Bilateral Loss of Vision after Spinal Anaesthesia on Dwarf Patient. Gen Med (Los Angeles) 9:345

Copyright: $(2021$ Kassa MW, et al. This is an open-access article distributed under the terms of the Creative Commons Attribution License, which permits unrestricted use, distribution, and reproduction in any medium, provided the original author and source are credited. 
of neural tissue can happen mainly at foramen magnum, thoracic and lumbar spine regions [6]. The size of the spinal canal is small and the dose and volume of spinal anaesthetic drug has to be adjusted to the total height in order to avoid high spinal block and toxicity. Hydrocephalus is an abnormal accumulation of Cerebrospinal fluid (CSF) leading to enlargement of the ventricles. The adult skull cannot expand and the effect of pressure affects the brain. Development of hydrocephalus is one of the common complications seen in dwarfism. In a study done on nine achondroplastic dwarfs with computerized tomography, skull and cervical spine films, and psychometric testing all had large ventricles that ranged from the top limits of normal to severe hydrocephalus $[7,8]$.

\section{CASE REPORT}

A 34-year-old dwarf young man with a height of $128 \mathrm{~cm}$ was admitted with a diagnosis of acute appendicitis. Four hours after admission he was taken to the theatre and removal of inflamed appendix was done. The anaesthesia done was spinal using $3 \mathrm{ml}(15 \mathrm{mg})$ heavy bupivacaine $0.5 \%$ and fentanyl $10 \mu \mathrm{cg}$ on right lateral position using 25 gauges cutting spinal needle. There was no technical problem during drug administration and no complication seen which demanded special attention or treatment intraoperative. The blood pressure, pulse rate and oxygen saturation were all within normal limits throughout surgery. He developed double vision after operation. It had started while he was in the recovery room. Eight hours post operation the patient noticed that he had lost his vision. He was reviewed by anaesthetist and ophthalmologist. He had light perception in both eyes with normal pupillary reflexes and normal fundus findings.

His head circumference was $99 \mathrm{~cm}$. Brain magnetic resonance image (MRI) was done which showed minimal ventricular enlargement with a conclusion of mild hydro cephalous (Figure 1). He was put on steroid treatment. The neuro-surgeon was consulted and a Ventriculo-peritoneal shunt operation was done successfully on the fourth post operation day. Intra-operative finding showed a gush flow of cerebro spinal fluid with increased pressure. On recovery from the anaesthesia he noted that his vision was a little blurred, but progressively his vision cleared and was able to see clearly. Repeat MRI after surgery showed the catheter in situ and drainage of the accumulated CSF from the ventricles (Figure 2).

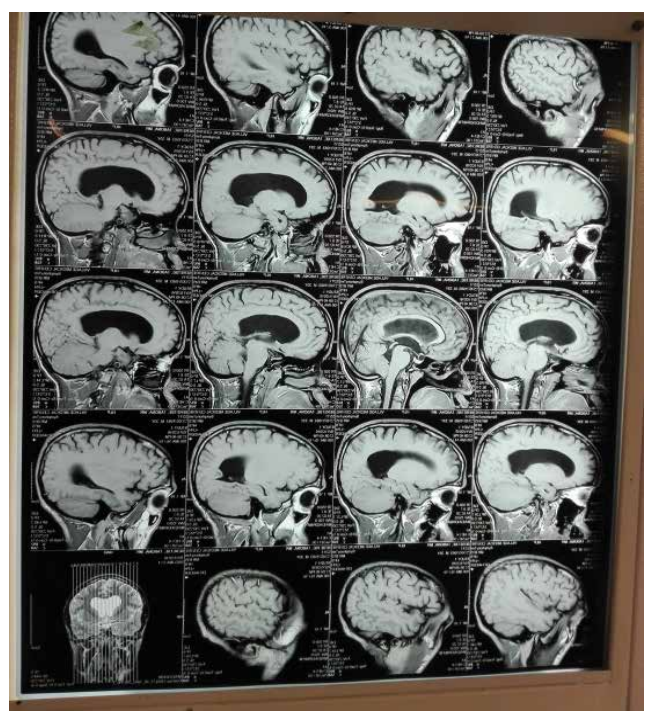

Figure 1: Minimal ventricular enlargement with a conclusion of mild hydro cephalous.

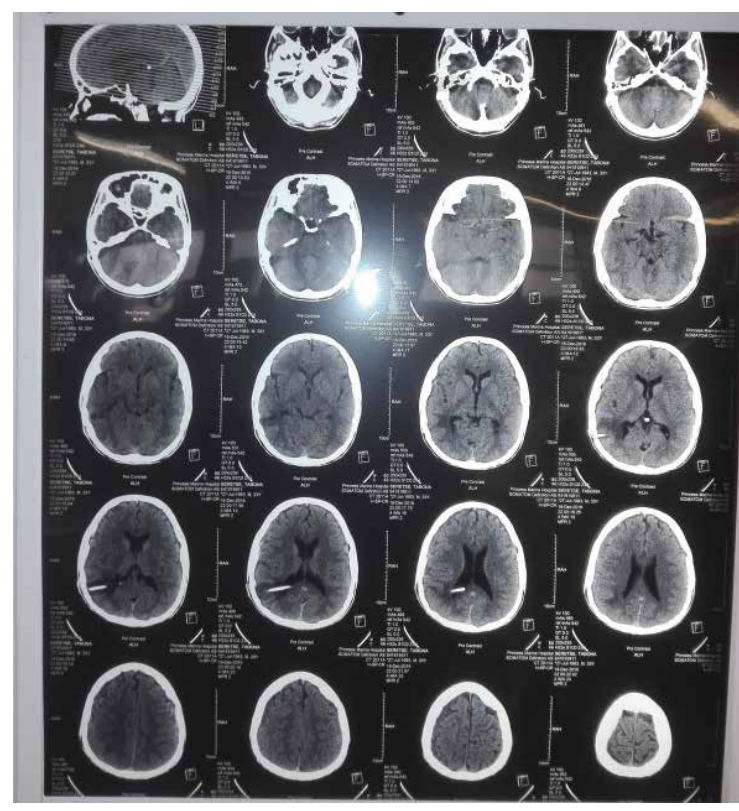

Figure 2: Repeat MRI after surgery showed the catheter in situ and drainage of the accumulated CSF from the ventricles.

Third post operation day from the second surgery the ophthalmologic examination revealed that right side visual acuity was $6 / 24$ and on the left side vision he was able to count fingers at 1 meter distance.

\section{DISCUSSION}

A study done in 2009 in USA on more than 5.6 million patients showed insignificant Postoperative visual loss after appendectomy $(0.12 / 10,000)$ [9]. A case report in 2003 showed a significant reduction of vision related to use of bupivacaine induced inflammation of the optic nerve after spinal anaesthesia [10]. We used a similar drug for spinal anaesthesia and the first initiated treatment was steroid on assumption of reducing of inflammation but there was no improvement in the patient's vision. In our patient there is a possibility of global rise of pressure within the skull resulting in a pre-existing increased intracranial pressure that could stay border line and lead to neurological damage. This is supported by the fact that hydrocephalous and increased intracranial pressure related to the hydrocephalous is a common complication of Dwarf patients as shown in a study by Erdinçler et al. [11].

The relationship of Achondroplasia and hydrocephalus has long been the subject of debate. Friedman and colleagues reported two patients with these conditions which responded dramatically to shunting procedures [12]. The effect of high pressure can manifest in different neurological manifestations such as hearing loss, visual loss.

A case of bilateral post-operative visual loss after spinal anaesthesia by Bezerra and others was documented to be from conversion disorder. This is relatively common and may include diplopia, nystagmus, visual field defects, and complete visual loss in which no physical cause is identified. In our case there is a definite problem identified and successful treatment reversed the visual loss [13]. A case report of post spinal subdural hematoma has also been reported and evacuation was an effective treatment like in our case [14]. A case report by Mossallem noted diplopia as an early presenting sign for visual loss of increased pressure secondary to bilateral subdural hematoma [15]. 
Our patient was given spinal anaesthesia without consideration of his feature of dwarfism. No suspicion was raised to consider increased intracranial pressure. Full dose and volume of spinal drug was given. Intraoperatively there was no complication noticed and duration of operation was short. Immediately post operation the patient developed diplopia followed by loss of vision. Examination of the pupillary reflex and fundus findings by ophthalmologist were normal with light perception, findings suggestive of cortical blindness.

Cortical blindness can result from global or focal ischemia, cardiac arrest, hypoxemia, intracranial hypertension and exsanguinating haemorrhage, vascular occlusion, thrombosis, intracranial haemorrhage, vasospasm, and emboli. In our patient there was undetected hydrocephalus during preanesthetic assessment with possible border line increase of intracranial pressure which was acutely further increased from different anaesthetic complications arising from spinal anaesthesia volume, possible sudden fluctuation of vital signs, position, and fluid overload.

\section{CONCLUSION}

This case illustrates the need to take into account the patients physical structure when administering spinal anaesthesia in dwarf patient and the importance of postoperative close follow up. A meticulous and detailed pre-anaesthetic assessment and planning in the mode of anaesthesia according to the findings on a dwarf patient is very important. The anaesthetic technique has to be individualized based on the patient's anatomical findings and presence of co-morbidities.

\section{REFERENCES}

1. Cheng JW, Cheng SW, Wei RL, Lu GC. Anti-vascular endothelial growth factor for control of wound healing in glaucoma surgery. The Cochrane Library. 2016.

2. Dattilo M, Biousse V, Bruce BB, Newman NJ. Functional and simulated visual loss. Handb Clin Neurol. 2016;139: 329-341.
3. Grover VK, Jangra K. Perioperative vision loss: A complication to watch out. Clin Pharmacol. 2012;28: 11.

4. Radziwill AJ, Vuadens P, Borruat FX, Bogousslavsky J. Visual disturbances and transurethral resection of the prostate: The TURP syndrome. Eur Neurol . 1997;38: 7-9.

5. Sahin C, Terzioglu U, Yigit G. sudden bilateral hearing loss after spinal anaesthesia. J Laryngol Otol.2015;129: 395-397.

6. Di Nardo SK. Anesthetic considerations for the achondroplastic dwarf. AANA J. 1988;56: 42.

7. Mueller SM, Bell W, CornellS, De Hamsher K, Dolan K. Achondroplasia and hydrocephalus a computerized tomographic, roentgenographic and psychometric study. Neurol . 1977;27: 430.

8. Ozcetin M, Arslan MT, Karapinar B. An achondroplasic case with foramen magnum stenosis, hydrocephaly, cortical atrophy, respiratory failure and sympathetic dysfunction. Iran J Pediatr. 2012;22: 121.

9. Shen Y, Drum M, Roth S. The prevalence of perioperative visual loss in the United States: A 10-year study from 1996 to 2005 of spinal, orthopedic, cardiac, and general surgery. Anesth Analg. 2009;109: 1534-1545.

10. Hosseini H, Brugieres P, Degos JD, Cesaro P. Neuromyelitis optica after a spinal anaesthesia with bupivacaine. J Mult Scler. 2013;9: 526-528.

11. Erdinçler P, Dashti R, Kaynar MY, Canbaz B, Çiplak N, Kuday C. Hydrocephalus and chronically increased intracranial pressure in achondroplasia. Childs Nerv Syst. 1997;13: 345-348.

12. Friedman WA, Mickle PJ. Hydrocephalus in achondroplasia: A possible mechanism. Neurosurg. 1980; 7: 150-153.

13. Bezerra DM, Bezerra EM, Junior SAJ, Amorim MA, Miranda DB. Postoperative visual loss due to conversion disorder after spine surgery: A case report. Braz J Anesthesiol. 2018;68: 91-95.

14. Schweiger V, Zanconato G, Lonati G, Baggio S, Gottin L, Vinay Shukla, et al. (2013) Intracranial subdural hematoma after spinal anesthesia for cesarean section. Case Rep Obstet Gynecol. 2013: 3.

15.Moussallem CD, El Yahchouchi CA, Charbel AC, Nohra G. Diplopia from subacute bilateral subdural hematoma after spinal anesthesia. J Bone joint surg Br. 2009;91: 1531-1532. 